\section{Treatment of inflamed ferret dental pulps with recombinant bone morphogenetic protein-7}

\author{
Rutherford RB, Gu K. Treatment of inflamed ferret dental pulps with recombinant \\ bone morphogenetic protein-7. Eur J Oral Sci 2000; 108: 202-206. \\ (c) Eur J Oral Sci, 2000
}

Recombinant human BMP-7 (bone morphogenetic protein-7, osteogenic protein-1) is osteogenic, dentinogenic and cementogenic when implanted into the appropriate tissue in vivo. However, most studies characterizing the induction of these tissues have implanted BMP-7 into freshly surgerized, clinically healthy tissues. To determine if BMP-7 is dentinogenic in inflamed dental pulps, we applied BMP-7 to inflamed ferret pulps. A single application of $5 \mu \mathrm{g}$ of a commercial preparation of lipopolysaccharide (LPS) from Salmonella typhimurium directly to the coronal pulp induced a reversible mixed inflammatory exudate of moderate intensity within $3 \mathrm{~d}$. Treatment with a single application of $2.5,7.5$ or $25 \mu \mathrm{g}$ recombinant human BMP-7/mg collagen (2 mg total mass/tooth) induced reparative dentinogenesis in controls but not LPS treated dental pulps. These data reveal that a single application of up to $50 \mu \mathrm{g} /$ tooth of exogenous recombinant BMP-7 is insufficient to induce reparative dentinogenesis in ferret teeth with reversible pulpitis. Given that pulp cells in the inflamed tissues likely retain the capacity to respond to exogenous BMP-7, it is possible that insufficient active recombinant protein is available to induce tissue formation in experimentally inflamed dental pulps.

\section{R. Bruce Rutherford, Keni Gu}

Department of Cariology, Restorative Sciences and Endodontics, School of Dentistry, University of Michigan, Ann Arbor, Michigan, USA
R. B. Rutherford, 1011 N. University, Ann Arbor, MI 48105-1078, USA

Telefax: +1-734-9361597

E-mail: rbruth@umich.edu

Key words: BMP-7; reparative dentinogenesis; pulpitis

Accepted for publication February 2000
Tertiary dentin matrices, formed in response to specific stimuli in adult teeth, are categorized as reparative or reactionary. Reparative dentin (RD) is a tertiary dentin matrix formed by new odontoblast-like cells in response to a specific stimulus after loss of the original odontoblasts, whilst reactionary dentin is formed by pre-existing odontoblasts (1). Clinical observations and experimental studies reveal that tertiary dentin forms in adult pulps subjacent to carious lesions, after partial removal of dentin (2), and after pulp exposure in germ-free rats (3), monkeys and humans (4-7). The controlled therapeutic induction of tertiary dentin matrices has long been a goal in clinical dentistry.

Bone morphogenetic proteins (BMPs) are a family of signaling molecules critically involved at various stages in the formation of a variety of tissues and organs including bones and teeth (8-10). Recombinant BMP-2, -4 and -7 are osteogenic $(8,11)$, dentinogenic (12-14) and cementogenic $(15,16)$ when applied directly to adult dermis, muscle, bone, dental pulp or the periodontium, respectively.

All published studies on BMP-induced reparative dentinogenesis have tested for efficacy using clinically healthy dental pulps (12-14). However, many patients who may be candidates for therapeutic dentinogenesis will present clinically vital teeth with an existing or history of recent pulpitis. Therefore the objectives of this study were to establish an animal model of reversible pulpitis and to test the effects of a single application of exogenous recombinant BMP-7 to the inflamed pulp tissue on reparative dentinogenesis. 


\section{Material and methods}

Experimental pulpitis was induced in adult ferret canines by the direct injection of a solution of water-soluble Salmonella typhimurium lipopolysaccharide (LPS; Sigma Chemical, St. Louis, MO, USA) (17). The ferrets were heavily sedated and the four canine teeth anesthetized by local infiltration. Sixty teeth (4 teeth in each of 15 animals) were treated randomly with 0 (normal saline control), 5 and $10 \mu \mathrm{g} /$ tooth (10 $\mu \mathrm{l}$ total volume/ tooth, $n=4$ /group) LPS and sealed with a glass ionomer material (ESPE-Premier, Norristown, PA, USA) for 1, 2, 3, 7 and $60 \mathrm{~d}$. The teeth were then harvested and processed for light microscopic histochemistry as previously described (14). The teeth were scored for extent and type of inflammatory infiltrate, and the frequency of intensity/ type category were recorded and analyzed statistically (Fisher's Exact Test). The criteria adapted from Heys et al. (18) as follows:

\section{Inflammatory response: Intensity}

1. No or slight inflammatory cell infiltrate at the exposure site;

2. Definite inflammatory cell infiltrate at the exposure site; or

3. Pronounced inflammatory cell infiltrate at the exposure site involving at least one-third of the coronal pulp.

Type

A. Predominately acute reaction characterized by a predominance of polymorphonuclear leukocytes (PMN);

B. Mixed acute and chronic reaction characterized by approximately equal numbers of PMN and mononuclear leukocytes;

C. Predominately chronic reaction characterized by a predominance of mononuclear leukocytes.

To determine if a single application of recombinant human BMP-7 induced reparative dentinogenesis in inflamed pulps, a concentration ranging study was performed on 32 adult ferret canines treated for $3 \mathrm{~d}$ with 0 (saline control) or $5 \mu \mathrm{g} \mathrm{LPS} /$ pulp. These teeth were then reopened, the remaining coronal pulp surgically amputated to the level of the cemento-enamel junction with a rotary dental instrument under copious saline irrigation. After hemostasis, $2 \mathrm{mg}$ (total mass) of a combination of BMP-7 and collagen carrier at $0,2.5,7.5$ and $25 \mu \mathrm{g} \mathrm{BMP-7/mg} \mathrm{of} \mathrm{collagen}$ carrier (Creative BioMolecules, Hopkinton, MA, USA) were added to the teeth ( $n=8$ teeth/BMP-7 treatment group/inflamed treatment group) and sealed for $30 \mathrm{~d}$. The BMP-7/collagen carrier $(11,14)$ was applied as described (12). The teeth were then harvested and analyzed histologically as described (12). Evaluation of all tissues was performed by an examiner blinded to the treatment groups.

Reverse transcriptase-polymerase chain reaction (RT-PCR) analyses of inflamed pulp tissues were performed exactly as described previously $(19,20)$. All animal protocols were approved by the University of Michigan Committee on the Use and Care of Animals.

\section{Results}

A priori, we predicted that a moderate inflammatory exudate comprising elements of acute and chronic inflammation (category $3 \mathrm{~B}$, above) would provide an appropriate test to determine the dentinogenic capacity of a single application of BMP-7/collagen. After $3 \mathrm{~d}, 5 \mu \mathrm{g}$ of LPS was moderately more effective than $10 \mu \mathrm{g}$ in inducing the desired level of inflammation, 3B (Fig. 1B) after $3 \mathrm{~d}(P=0.07)$. All the inflammatory lesions were restricted to the crowns of the teeth as judged by the position of the lesion relative to the cementoenamel junction (Fig. 1B).

This category of inflammation in teeth treated with $5 \mu \mathrm{g}$ LPS appeared to be reversible in the immature ferret canine teeth utilized in this study. All teeth treated with saline or $5 \mu \mathrm{g}$ LPS remained vital, while 3 of 4 treated with $10 \mu \mathrm{g}$ were nonvital after $60 \mathrm{~d}$. In the vital teeth, the root-tip formation was normal as evidenced by histological examination (Fig. 1C). No histological evidence of reparative dentin formation was observed in any of these teeth. During this period the animals did not receive analgesics, manifested no abnormal behavior, continued to eat normal laboratory chow, and gained weight consistent with their ages.

A single application of BMP-7/collagen at any concentration tested failed to induce reparative dentinogenesis in the LPS-treated teeth (Table 1). In contrast, $92 \%$ of the saline treated control teeth subsequently treated with BMP-7/collagen were positive for reparative dentin (Table 1, Fig. 2). Carrier alone failed to induce reparative dentin under all tested conditions.

To determine if LPS-associated inflammatory processes altered the expression of BMP receptors by pulp cells, we analyzed total RNA from dental pulp treated for $3 \mathrm{~d}$ with saline (data not shown) or $5 \mu \mathrm{g}$ LPS for these genes associated with BMP responsiveness by RT-PCR (Fig. 3). The identical set of mRNAs for BMPR-1A, $-1 \mathrm{~B}$, and -II, was detected in both control and LPS-treated tissues. 

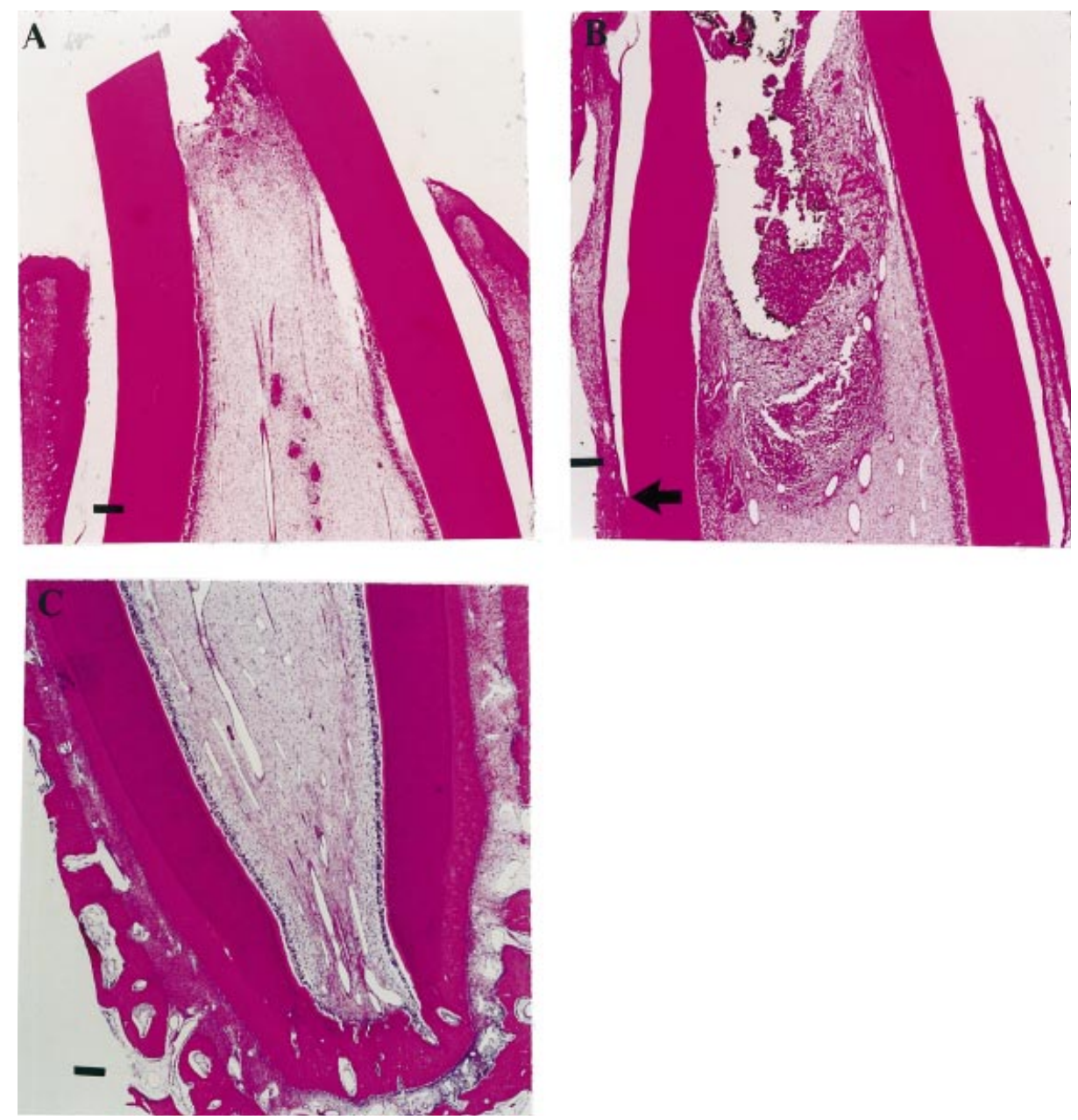

Fig. 1. Photomicrographs of partially amputated adult ferret canines pulps inoculated with sterile saline (A) or $5 \mu \mathrm{g}$ LPS (B) for $3 \mathrm{~d}$. The inflammatory lesion caused by LPS is more severe than saline injected pulps and restricted to the coronal pulp (arrow at cemento-enamel junction). Photomicrograph of a representative ferret canine root apex (C) $60 \mathrm{~d}$ after treatment with $5 \mu \mathrm{g}$ LPS. Pulp and periapical tissues appear normal and free of inflammatory infiltrates. Original magnification $\times 10$. Bar equals $100 \mu \mathrm{m}$.

Table 1

Effect of LPS-induced pulpitis on BMP-7-induced reparative dentinogenesis

\begin{tabular}{lcccc}
\hline & \multicolumn{4}{c}{ BMP-7 $(\mu \mathrm{g} / \mathrm{mg}$ carrier $)$} \\
\cline { 2 - 5 } & 0 & 2.5 & 7.5 & 25 \\
\hline 0 (saline control) & $0 / 8$ & $7 / 8$ & $7 / 8$ & $8 / 8$ \\
$5 \mu \mathrm{g}$ LPS & $0 / 8$ & $0 / 8$ & $0 / 8$ & $0 / 8$ \\
\hline
\end{tabular}

\section{Discussion}

BMP are osteogenic (8), dentinogenic (reviewed in $(21))$, and cementogenic $(15,16)$. However, most of the studies testing the capacity of single applications of recombinant BMP protein to induce tissue regeneration have placed the protein, absorbed to an appropriate carrier, into freshly surgerized healthy tissues. In the realm of therapeutic dentinogenesis, it is likely that in many clinical instances where such a therapy might apply, the pulp tissue could be inflamed with or without clinical symptoms. Hence it is important, at least for tertiary dentinogenesis, that BMP protein therapy be efficacious in inflamed tissue. Therefore, we have developed a model of experimental pulpitis using commercial bacterial LPS and young adult, ferret canine teeth.

Ferrets were chosen because others have demonstrated that ferret teeth respond to specific stimuli by elaborating tertiary dentin matrices (22). In addition, we chose to test a solution of commercial, water soluble bacterial LPS (17) because it promised to be more quantifiable and reproducible than dental caries, plaque or live anaerobic bacteria. Our data demonstrate that a single injection of a solution containing $5 \mu \mathrm{g}$ of $S$. typhimurium LPS injected directly into a surgically exposed pulp reproducibly induced substantial inflammatory changes in ferret pulps within $3 \mathrm{~d}$. The 


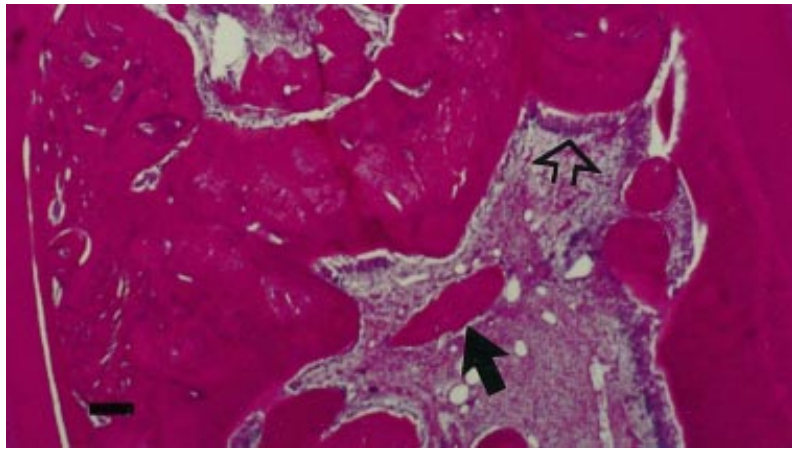

Fig. 2. Photomicrograph of coronal pulp of control saline treated tooth subsequently treated with a single application of $2.5 \mu \mathrm{g}$ recombinant BMP-7/mg carrier $30 \mathrm{~d}$ after treatment. Islands of reparative dentin (closed arrow) may represent particles of the BMP-7/carrier that fragmented from the main mass of material upon insertion. Odontoblast-like cells line the reparative dentin-pulp junction (open arrow). Original magnification $\times 25$. Bar equals $50 \mu \mathrm{m}$.

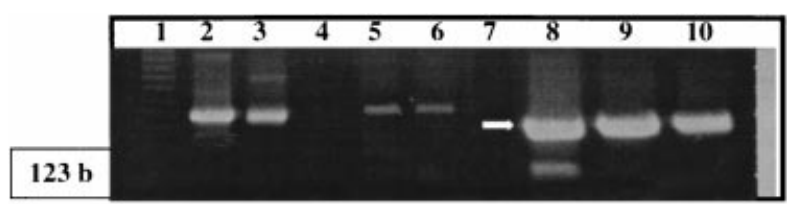

Fig. 3. Expression of genes associated with responsiveness to BMP. RT-PCR analysis of total RNA from adult LPS-treated ferret pulp and normal ferret and mouse skin included for size comparison. Lane 1. m.w. markers; lanes 2 and 3. BMPR-IA; 4. water control; lanes 5 and 6 BMPR-II; lane 7. blank; lanes 8, 9 and 10. BMPR-II. Lanes 3, 6, 9 mouse and 10 ferret skin controls. An arrow marks the appropriate band. Since these PCR primers were developed from human, they bind to ferret cDNA with varying efficiencies which results in the variation in band intensity and multiple bands.

inflammatory changes induced by this regimen did not lead to pulpal death and cessation of root maturation within $60 \mathrm{~d}$ (Fig. 1C). Therefore, we consider the inflammatory changes which follow a single injection of $5 \mu \mathrm{g}$ of $S$. typhimurium LPS to be largely reversible in young, adult ferret canine teeth.

Previous studies have demonstrated that a single application of $2.5 \mu \mathrm{g}$ recombinant human BMP-7/ mg collagen carrier to clinically healthy monkey teeth is sufficient to induce reparative dentinogenesis $(12,14)$. Mature (R.B. Rutherford, unpublished observations) and immature ferret canines pre-treated with saline rather than LPS formed reparative dentin in $92 \%$ of teeth tested (Table 1, Fig. 2). This study extends earlier observations that BMP-7 is dentinogenic in monkeys to ferrets. In addition, increasing the concentration and the total amount of recombinant human BMP-7, but not the total mass of the BMP/carrier combination, applied to each tooth did not alter the amount of RD formed. The time course of RD formation was not examined in these experiments.

Exogenous BMP-7 failed to induce reparative dentin in reversibly inflamed teeth (Table 1). The reasons for this failure are not clear. Failure cannot be due to inactive $\mathrm{BMP} /$ carrier, since aliquots from the same preparation induced reparative dentinogenesis in saline-treated teeth.

We have detected the expression of BMP-2, -4 , and -7 and BMP receptor mRNA in human pulps and cultured pulp cells by the RT-PCR $(19,23)$. We have also determined that these primers and a pair developed from our published human cDNA sequence for human dentin sialophosphophoryn (20), as well human collagen type I, detect expression of the mRNA for these genes in total RNA extracted from healthy adult ferret dental pulps (data not shown). Total RNA from control (data not shown) or LPS-treated ferrets pulps (Fig. 3) express BMP receptors. Therefore, it seems unlikely that LPS treatment as applied in these studies substantially alters the capacity of resident pulp cells to respond to BMP-7. It is possible that the levels of the BMP antagonistic binding proteins noggin or chordin (24) are sufficiently elevated in inflamed pulps to inactive the exogenous protein. Alternatively, the recombinant BMP-7 protein may be rapidly denatured in inflamed tissue so that even amounts 10-fold higher than necessary to induce a reparative response in non-inflamed tissue are ineffective. We conclude that a single application of a therapeutic dressing comprising BMP-7 and a bovine bone-derived collagen carrier fails to induce reparative dentin formation in an animal model of reversible pulpitis.

Acknowledgements - The authors appreciate the excellent technical assistance of Sue Ryan and Marge Tucker. This work was supported by grants from NIDCR DE11923 and the American Association of Endodontists Foundation. A portion of this work was published in Transactions Vol. 13, 1999 of the Academy of Dental Materials.

\section{References}

1. Smith AJ, Cassidy N, Perry H, Begue-Kirn C, Ruch JV, Lesot H. Reactionary dentinogenesis. Int J Dev Biol 1995; 39: $273-280$.

2. Seltzer S, Bender IB. Pulp capping and pulpotomy. In: Seltzer S, Bender IB, eds. Biologic Considerations in Dental Procedures. Philadelphia: J.B. Lippicott and Co., 1984; 281-302.

3. Kakehashi S, Stanley HR, Fitzgerald RJ. The effects of surgical exposure of dental pulps in germ-free and conventional laboratory rats. Oral Surg 1965; 20: 340-344.

4. CVEK M. A clinical report on partial pulpotomy and capping with calcium hydroxide in permanent incisors with complicated crown fracture. J Endodont 1978; 4: 232-237. 
5. Fitzgerald M. Cellular mechanics of dentinal bridge repair using 3H-thymidine. J Dent Res 1979; 66: 2198-2206.

6. Cvek M, Granath L, Cleaton JP, Austin J. Hard tissue barrier formation in pulpotomized monkey teeth capped with cyanoacrylate or calcium hydroxide for 10 and 60 minutes. J Dent Res 1987; 66: 1166-1174.

7. Fitzgerald M, Heys RJ. A clinical and histological evaluation of conservative pulpal therapy in human teeth. Oper Dent 1991; 16: 101-112.

8. KingSLEY DM. What do BMPs do in mammals? Clues from the mouse short-ear mutation. TIG 1994; 10: 16-21.

9. Hogan BL. Bone morphogenetic proteins in development. Curr Opin Genet Dev 1996; 6: 432-438.

10. TheslefF I, Sharpe P. Signaling networks regulating dental development. Mech Devel 1997; 67: 111-123.

11. Sampath TK, Maliakal JC, Hauschka PV, Jones WK, Sasak H, Tucker RF, White KH, Coughlin JE, Tucker MM, Pang RHL, Corbett C, Oskaynak E, Oppermann H, Rueger DC. Recombinant human osteogenic protein-1 (hOP-1) induces new bone formation in vivo with a specific activity comparable with natural bovine osteogenic protein and stimulates osteoblast proliferation and differentiation in vitro. $J$ Biol Chem 1992; 267: 20352-20362.

12. Rutherford RB, Wahle J, Tucker M, Rueger D, CHARETTE M. Induction of reparative dentin formation in monkeys by recombinant human osteogenic protein-1. Arch Oral Biol 1993; 38: 571-576.

13. Nakashima M. Induction of dentin formation on canine amputated pulp by recombinant human bone morphogenetic proteins (BMP)-2 and -4. J Dent Res 1994; 73: $1515-1522$.

14. Rutherford RB, Spangberg L, Tucker M, Rueger D, Charette M. Time course of the induction of reparative dentin formation in monkeys by recombinant human osteogenic protein-1. Arch Oral Biol 1994; 39: 833-838.
15. Ripamonti U, Heliotis M, Rueger DC, Sampath TK. Induction of cementogenesis by recombinant human osteogenic protein-1 (hop-1/bmp-7) in the baboon (Papio ursinus). Arch Oral Biol 1996; 41: 121-126.

16. Giannobile WV, Ryan S, Shih MS, Su DL, Kaplan PL, CHAn TC. Recombinant human osteogenic protein-1 (OP-1) stimulates periodontal wound healing in class III furcation defects. J Periodontol 1998; 69: 129-137.

17. Okiji T, Morita I, Sunada I, Murota S. Involvement of arachidonic acid metabolites in increases in vascular permeability in experimental dental pulpal inflammation in the rat. Arch Oral Biol 1989; 34: 523-528.

18. Heys DR, Fitzgerald M, Heys RJ, Chiego DJ. Healing of primate dental pulps capped with Teflon. Oral Surg Oral Med Oral Pathol 1990; 69: 227-237.

19. Gu K, Smoke RS, Rutherford RB. Expression of genes for bone morphogenetic proteins and receptors in human dental pulp. Arch Oral Biol 1996; 41: 919-923.

20. Gu K, Chang SR, Slaven MS, Clarkson BH, Rutherford RB, Ritchie HH. Human dentin phosphophoryn nucleotide and amino acid sequence. Eur J Oral Sci 1998; 106: 1043-1047.

21. Rutherford RB, Fitzgerald M. A new biological approach to vital pulp therapy. Crit Rev Oral Biol Med 1995; 6: 218-229.

22. Smith AJ, Tobias RS, Cassidy N, Plant CG, Browne RM, Begue-Kirn C, Ruch JV, Lesot H. Odontoblast sitmulation in ferrets by dentine matrix components. Arch Oral Biol 1994; 39: 13-22.

23. Buurma B, Gu K, Rutherford RB. Transplantation of human pulpal and gingival fibroblasts attached to synthetic scaffolds. Eur J Oral Sci 1999; 107: 282-289.

24. Gazzerro E, Gangil V, Canalis E. Bone morphogenetic proteins induce the expression of noggin, which limits their activity in cultured rat osteoblasts. J Clin Inves 1998; 102: 2106-2114. 